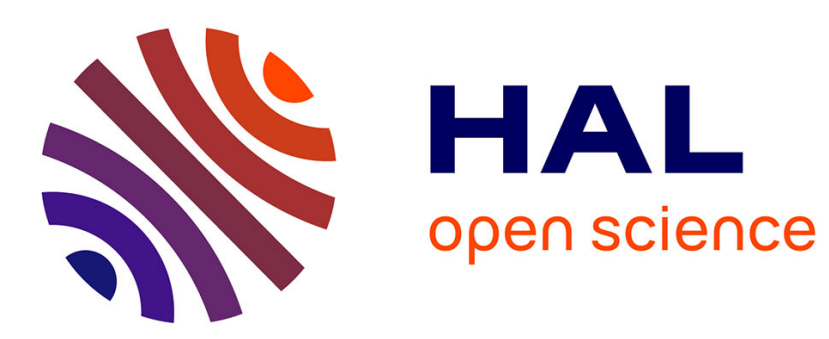

\title{
Thermochemical and Mass Transport Modelling of the Chemical Vapour Deposition of Si1-xGex
}

\author{
M. Pons, E. Blanquet, C. Bernard, H. Rouch, J. Dedulle, R. Madar
}

\section{To cite this version:}

M. Pons, E. Blanquet, C. Bernard, H. Rouch, J. Dedulle, et al.. Thermochemical and Mass Transport Modelling of the Chemical Vapour Deposition of Si1-xGex. Journal de Physique IV Proceedings, 1995, 05 (C5), pp.C5-63-C5-70. 10.1051/jphyscol:1995504 . jpa-00253760

\section{HAL Id: jpa-00253760 https://hal.science/jpa-00253760}

Submitted on 1 Jan 1995

HAL is a multi-disciplinary open access archive for the deposit and dissemination of scientific research documents, whether they are published or not. The documents may come from teaching and research institutions in France or abroad, or from public or private research centers.
L'archive ouverte pluridisciplinaire HAL, est destinée au dépôt et à la diffusion de documents scientifiques de niveau recherche, publiés ou non, émanant des établissements d'enseignement et de recherche français ou étrangers, des laboratoires publics ou privés. 


\title{
Thermochemical and Mass Transport Modelling of the Chemical Vapour Deposition of $\mathrm{Si}_{1-x} \mathrm{Ge}_{x}$
}

\author{
M. Pons, E. Blanquet*, C. Bernard*, H. Rouch**, J.M. Dedulle** and R. Madar** \\ S2MC, URA 413/ENSEEG/INPG, BP. 75, Domaine Universitaire, 38402 Saint-Martin d'Hères, France \\ * LTPCM, URA 29/ENSEEG/INPG, BP. 75, Domaine Universitaire, 38402 Saint-Martin d'Hères, France \\ ** LMGP, URA 1109/ENSEEG/INPG, BP. 46, Domaine Universitaire, 38402 Saint-Martin d'Hères, \\ France
}

\begin{abstract}
The purpose of this article is to present, for the chemical vapour deposition process, mass transport models with near local thermochemical equilibrium imposed in the gas-phase and at the deposition surface. The theoretical problems arising from the linking of the two approaches, thermodynamics and mass transport, are shown and a solution procedure is proposed. As an illustration, selected results of thermodynamic and mass transport analysis and of the coupled approach showed that, for the deposition of $\mathrm{Si}_{1-\mathrm{x}} \mathrm{Ge}_{\mathrm{x}}$ solid solution at $1300 \mathrm{~K}$ (system $\mathrm{Si}-\mathrm{Ge}-\mathrm{Cl}-\mathrm{H}-\mathrm{Ar}$ ), the thermodynamic heterogeneous stability of the reactive gases and the thermal diffusion led to the germanium depletion of the deposit.
\end{abstract}

\section{INTRODUCTION}

The modelling approaches are generally based (a) on kinetic computations, (b) on thermochemical equilibrium computations, (c) on mass transport computations linked with chemical kinetic data and (d) on mass transport linked with local thermochemical equilibrium. Thermodynamic analysis addresses several important issues with respect to CVD. Whether a given chemical reaction is feasible is perhaps the most important of these. Once it is decided that a reaction is feasible, thermodynamic calculations can frequently provide information on the partial pressures of the gaseous species and on the nature of the solid phases. Importantly, it provides an upper limit of what to expect under specified conditions. However, this approach is not expected to yield the equilibrium or non-equilibrium state corresponding to the temperature, the pressure and the concentrations actually established in the gas phase or at the solid-gas interface. In an open, flowing CVD system, to correctly interpret the involved phenomena, it will be necessary to study chemically reacting flows with non-uniform flow and temperature fields [1-2]. In special situations, chemical equilibrium arguments can be used coupled with transport phenomena [3-8] but in general, an accurate representation of the process will require consideration of chemical kinetics [9-14]. Whereas hydrodynamic models are generally applicable, a separate chemical model stating the relevant homogeneous and heterogeneous reaction pathways and rate constants must be specified for each CVD process. The lack of detailed chemical kinetic data seems to be the most important limitation in CVD modelling. Even for the deposition of pure elements, the number of simultaneous gas phase and surface reactions and therefore of species which must be taken into account can be as high as tens or hundreds. Another modelling route involves the formulation of an overall kinetics model and the extraction of parameters from growth rate data; these last approaches have been relatively successful in predicting growth rates in CVD reactors operating under a limited range of process conditions [see for example 15].

In this paper, we propose a modelling route linking thermochemical databases and equilibrium calculations with mass transport calculations. The advantage of this coupled approach is that, for a large variety of chemical systems, reliable data are available. The main drawback is that the relevant models are restricted to near local thermochemical equilibrium (LTCE) conditions. However, the thermochemistry of the reactants, products and intermediates coupled with mass transport can be useful as it provides a framework into which a complete chemical kinetic model must fit. In simple terms, the kinetics linked with mass transport must be consistent with this analysis. This concept only required the knowledge of the gaseous species and solid phases which would appear [8-10]. A general procedure for implementing species balances with near LTCE constraint is more complex and will be shown. It is important to note that 
this general procedure is able to handle quasi-equilibrium models and/or surface reaction rates in order to express more realistic heterogeneous kinetics. The application of this concept to the deposition of $\mathrm{Si}_{1-x} \mathrm{Ge}_{\mathrm{x}}$ alloys will be analysed.

\section{THERMODYNAMIC EQUILIBRIUM ANALYSIS}

The only solid phase in the $\mathrm{Si}-\mathrm{Ge}-\mathrm{Cl}-\mathrm{H}-\mathrm{Ar}$ system is the $\mathrm{Si}_{1-\mathrm{x}} \mathrm{Ge}_{\mathrm{x}}$ solid solution which covers the entire composition range. It is important to know and to control the stoichiometry of the coating. The thermodynamic calculations were performed with the Melange software package [16] linked to the SGTE databank [17]. The gaseous species which were taken into account are listed in Table 1. The only solid phase considered was the $\mathrm{Si}_{1-x} \mathrm{Ge}_{\mathrm{x}}$ solid solution. For the $\mathrm{Si}-\mathrm{H}-\mathrm{Cl}$ system, a coherent set of data is available in the SGTE databank. A more recent source of data is also available [18]. For the $\mathrm{Ge}-\mathrm{H}-\mathrm{Cl}$ system, none of the needed data is available. Therefore, they were estimated by ponderation methods for $\mathrm{GeHCl}_{3}, \mathrm{GeH}_{2} \mathrm{Cl}_{2}$ and $\mathrm{GeH}_{3} \mathrm{Cl}$ and by invoking the similarity in the behaviour of the $\mathrm{Ge}$ and $\mathrm{Si}$ elements with respect to $\mathrm{H}$ and $\mathrm{Cl}$ atoms for the other gaseous species [19]. These methods certainly provide rough values but the concerned gaseous species are of less importance in the relevant experiments. The other possible gaseous species are generally neglected.

Table 1 : Gaseous species used in the model (the thermodynamic data of gascous species written in italic were estimated).

\begin{tabular}{|c|c|c|c|c|c|c|c|}
\hline $\mathrm{SiH}_{4}$ & $\mathrm{SiH}_{3}$ & $\mathrm{SiH}_{2}$ & $\mathrm{SiH}$ & $\mathrm{SiCl}_{4}$ & $\mathrm{SiCl}_{3}$ & $\mathrm{SiCl}_{2}$ & $\mathrm{SiCl}$ \\
\hline $\mathrm{GeH}_{4}$ & $\mathrm{GeH}_{3}$ & $G e H_{2}$ & $G e \bar{H}$ & $\mathrm{GeCl}_{4}$ & $\mathrm{GeCl}_{3}$ & $\mathrm{GeCl}_{2}$ & $\mathrm{GeCl}$ \\
\hline $\mathrm{Si}_{2} \mathrm{H}_{6}$ & $\mathrm{Si}_{2} \mathrm{Cl}_{6}$ & $\mathrm{Si}$ & $\mathrm{SiHCl}_{3}$ & $\mathrm{SiH}_{2} \mathrm{Cl}_{2}$ & $\mathrm{SiH}_{3} \mathrm{Cl}$ & $\mathrm{HCl}$ & $\mathrm{H}_{2}$ \\
\hline $\mathrm{Ge}_{2} \mathrm{H}_{6}$ & $\mathrm{Ge}_{2} \mathrm{Cl}_{6}$ & $\mathrm{Ge}$ & $\mathrm{GeHCl}_{3}$ & $\mathrm{GeH}_{2} \mathrm{Cl}_{2}$ & $\mathrm{GeH} \mathrm{HCl}_{3} \mathrm{Cl}$ & $\mathrm{Ar}$ & $\mathrm{He}$ \\
\hline
\end{tabular}

For the Gibbs' free energy description of the Si-Ge solid solution, we have used the recent values published by $\mathrm{C}$. Bergman et al. [20]. The Si-Ge-Cl-H-Ar system involves a condensed phase and a gaseous phase (5 elements, 2 phases). The thermodynamic calculations require the knowledge of total pressure, temperature, argon dilution if necessary, $\mathrm{Y}_{\mathrm{Ge}}$ and $\mathrm{Cl} / \mathrm{H}$. The quantity $\mathrm{Y}_{\mathrm{Ge}}$ is defined as the ratio of the inlet molar fraction of gaseous species containing germanium over the inlet molar fraction of gaseous species containing germanium and silicon. The quantity $\mathrm{Cl} / \mathrm{H}$ is defined as the ratio of the number of $\mathrm{Cl}$ atoms over the number of $\mathrm{H}$ atoms introduced in the reactor.

The pressure, temperature and $\mathrm{Y}_{\mathrm{Ge}}$ ranges investigated are $10^{2}$ to $10^{5} \mathrm{~Pa}, 600$ to $1400 \mathrm{~K}$ and 0 to 1 , respectively, for an initial mixture of $\mathrm{GeH}_{4}$ and $\mathrm{SiH}_{4}$ diluted (from 1 to $3 \%$ ) in Ar. Figure 1 represents the evolution of the germanium fraction in the solid, $\mathrm{X}_{\mathrm{Ge}}$, as a function of temperature, for different gaseous mixtures and for different germanium fraction, $Y_{\mathrm{Ge}}$, in the inlet mixture. In all cases, the simulation has provided identical values of $X_{G e}$ and $Y_{G e}$ because the silicon and germanium containing species are completely cracked in the gas phase. The situation is quite different if more stable gaseous species containing $\mathrm{Ge}$ and $\mathrm{Si}$ like the chlorides are used. Two types of experiments have been modelled. In the first one, small amounts of $\mathrm{HCl}$ were introduced in the $\mathrm{Ar}-\mathrm{GeH}_{4}-\mathrm{SiH}_{4}$ mixture and in the second one, a mixture of $\mathrm{Ar}-\mathrm{GeCl}_{4}-\mathrm{SiH}_{4}$ was used. For the two investigated mixtures, the general trends are similar. When $\mathrm{HCl}$ is used, the $\mathrm{Cl} / \mathrm{H}$ ratio is small and fixed. In this case, only an effect of composition is observed; the $\mathrm{Y}_{\mathrm{Ge}^{-}}$ $\mathrm{X}_{\mathrm{Ge}}$ gap is slightly increased as the temperature increases for the higher values of $\mathrm{Y}_{\mathrm{Ge}}$. When $\mathrm{GeCl}_{4}$ is used, the $\mathrm{Cl} / \mathrm{H}$ ratio varies. In this case, the $\mathrm{Y}_{\mathrm{Ge}}-\mathrm{X}_{\mathrm{Ge}}$ gap increases with the temperature and with the $\mathrm{Cl} / \mathrm{H}$ ratio.

As a partial conclusion, this a priori equilibrium approach showed that, at a pressure of $133 \mathrm{~Pa}$ used for experiments, the important parameters for the control of the $\mathrm{Ge}$ fraction in the coating are the $\mathrm{Cl} / \mathrm{H}$ ratio and the temperature. The experimental results obtained with $\mathrm{HCl}$ and without $\mathrm{HCl}$ are however far below the calculated values [19]. These results suggest that mass transport phenomena could be of importance during the deposition process. To investigate the influence of transport phenomena on equilibrium chemistry, the linking of thermochemical data, equilibrium calculations and mass transport simulations was performed for $\mathrm{SiH}_{4}-\mathrm{GeCl}_{4}-\mathrm{Ar}$ mixtures. This approach is expected to yield the near local thermochemical equilibrium state corresponding to the temperature, the pressure and the concentrations actually established in the gas phase or at the solid-gas interface. 


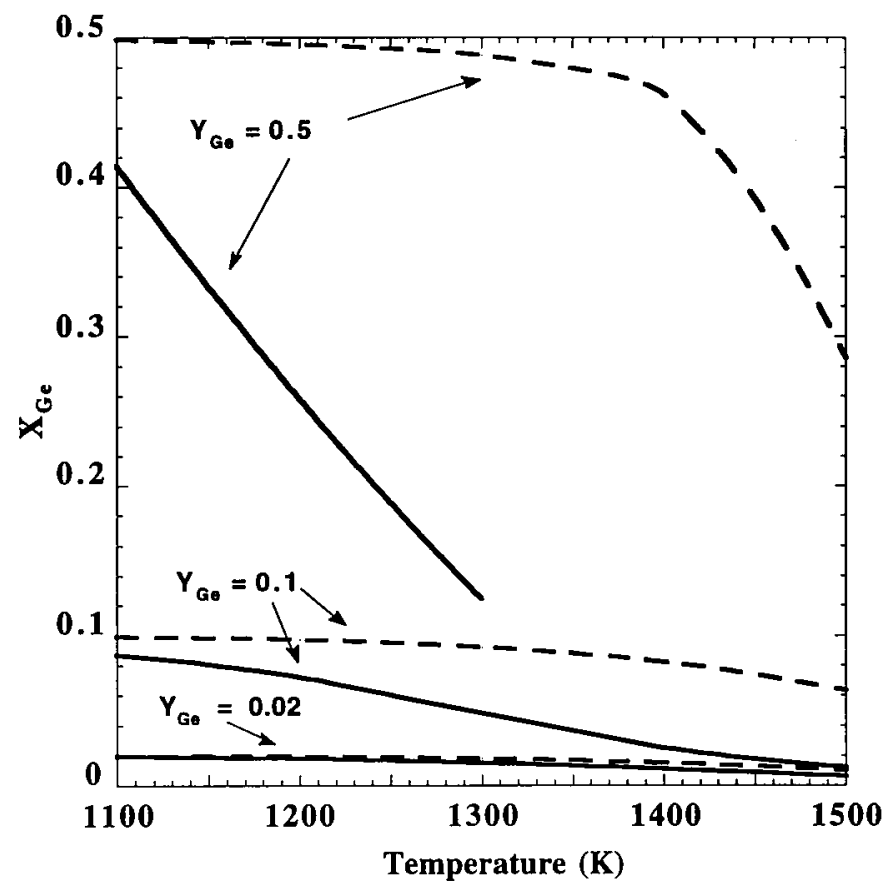

Figure 1 : Evolution of $\mathrm{X}_{\mathrm{Ge}}$ as a function of the temperature for different $\mathrm{Y}_{\mathrm{Ge}}$ values and different gaseous mixture $(\mathrm{P}=133$ $\mathrm{Pa}$.

$$
\begin{aligned}
& \operatorname{Ar}(99 \%)-\mathrm{SiH}_{4}+\mathrm{GeCl}_{4}(1 \%)-\frac{\mathrm{Cl}}{\mathrm{H}}=\frac{\mathrm{Y}_{\mathrm{Ge}}}{1-\mathrm{Y}_{\mathrm{Ge}}} \\
& \operatorname{Ar}(89 \%)-\mathrm{SiH}_{4}+\mathrm{GeH}_{4}(1 \%)-\mathrm{H}_{2}(9.96 \%)-\mathrm{HCl}(0.04 \%)
\end{aligned}
$$

\section{MASS TRANSPORT - NEAR LTCE MODEL}

The model was made suitable for the silicon-germanium deposition reactor presented in figure 2(a) for simulation purposes. This reactor was optimized by experiments and by mass transport modelling using a simplified kinetic pathway [19]. The governing equations for multicomponent (see table 1) mass transport are well known (table 2). The multicomponent diffusion is described by generalizing the binary diffusion to a $\mathrm{N}$-component system. The source term, $\mathrm{S}_{\mathrm{i}}$, represents the rate of creation or depletion of species $\mathrm{i}$ by homogeneous chemical reaction and must be calculated with the near LTCE concept. From a guessed concentration field $\left(w_{i}, i=1 \ldots N-1\right)$, Gibbs energy minimization at each grid point of the reactor gives a new set of $\mathrm{w}_{\mathrm{ieq}}$; the near-equilibrium sources terms $S_{\text {ieq }}$, which vanish when equilibrium is reached, can be obtained from:

$$
S_{i_{e q}}=\nabla \cdot\left(\rho \underline{v w}_{i_{e q}}-\sum_{j=1}^{N-1} \rho D_{i j} \nabla w_{j_{e q}}-D_{i}^{T} \frac{\nabla T}{T}\right) \quad i=1 \ldots N-1
$$

The sources terms $\mathrm{S}_{\mathrm{ieq}}$ cannot be directly inserted to continue the iterative modelling and to compute a new set of $w_{i}$ from $S_{\text {ieq }}$ guessed field. The constraints associated with LTCE and mass transport analysis are different. LTCE calculations assume elements and mass conservation in a closed chemical system (the stoichiometry of the reactions is respected). Mass transport calculation assumes only mass conservation in an open chemical system. It is necessary, to import the data of LTCE calculation into the transport equations, to find the intersection between the two spaces of solutions. Projective methods [19] are used to calculate $S_{i}$ for iteration $n+1$ from $w_{i e q}$ calculated by equation (9) from $w_{i}$ and calculated at iteration $n$ (PROJ is the projection operator): 
$\mathrm{s}_{\mathrm{i}}($ iter. $\mathrm{n}+\mathrm{l})=\operatorname{PROJ}\left[\mathrm{s}_{\mathrm{i}_{\mathrm{eq}}}(\right.$ iter. $\left.\mathrm{n})\right]$

The vector $\underline{S}$ must be orthogonal to the matrix $A$ of the stoichiometric coefficients defined by $E$ rows and $\mathrm{N}$ columns; $\mathrm{E}$ is the number of element and $\mathrm{N}$ the number of gaseous species. The mass transport-LTCE model to solve is :

$$
\nabla \cdot\left(\rho \underline{v w}_{i}-\sum_{j=1}^{N-1} \rho D_{i j} \nabla w_{j}-D_{i}^{T} \frac{\nabla T}{T}\right)=S_{i} \quad i=1 \ldots N-1
$$

Minimization of $\mathrm{G}\left(\mathrm{P}, \mathrm{T}, \mathrm{w}_{1} \ldots \mathrm{w}_{\mathrm{N}-1}\right)$ at each grid point

$$
\underline{S} \in\langle A\rangle^{\perp}
$$

The iterative procedure for homogeneous phenomena is stopped when $w_{i}->w_{\text {ieq }}$ e.g., when near LTCE is reached at each grid point of the reactor.

\begin{tabular}{|c|c|c|}
\hline Name & Definition & \\
\hline Mass conservation & $\nabla \cdot(\rho \underline{v})=0$ & (1) \\
\hline Momentum conservation & $\rho \underline{v} \nabla \underline{v}=\nabla \cdot \underline{\tau}-\nabla P+\rho \underline{g}$ & (2) \\
\hline Energy conservation & $\nabla \cdot\left(\rho \mathrm{C}_{p} \underline{\mathrm{v} T}\right)=\nabla \cdot(\lambda \nabla \mathrm{T})$ & (3) \\
\hline 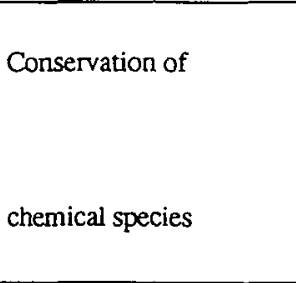 & 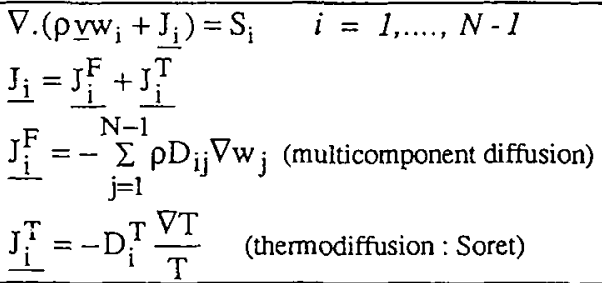 & $\begin{array}{l}\text { (4) } \\
\text { (5) } \\
\text { (6) } \\
\text { (7) }\end{array}$ \\
\hline Density & $\rho=\frac{P}{\operatorname{RT} \sum_{i=1}^{N}\left(w_{i} / M_{i}\right)}$ & (8) \\
\hline
\end{tabular}

Table 2 : The equations of transport for multicomponent mixtures

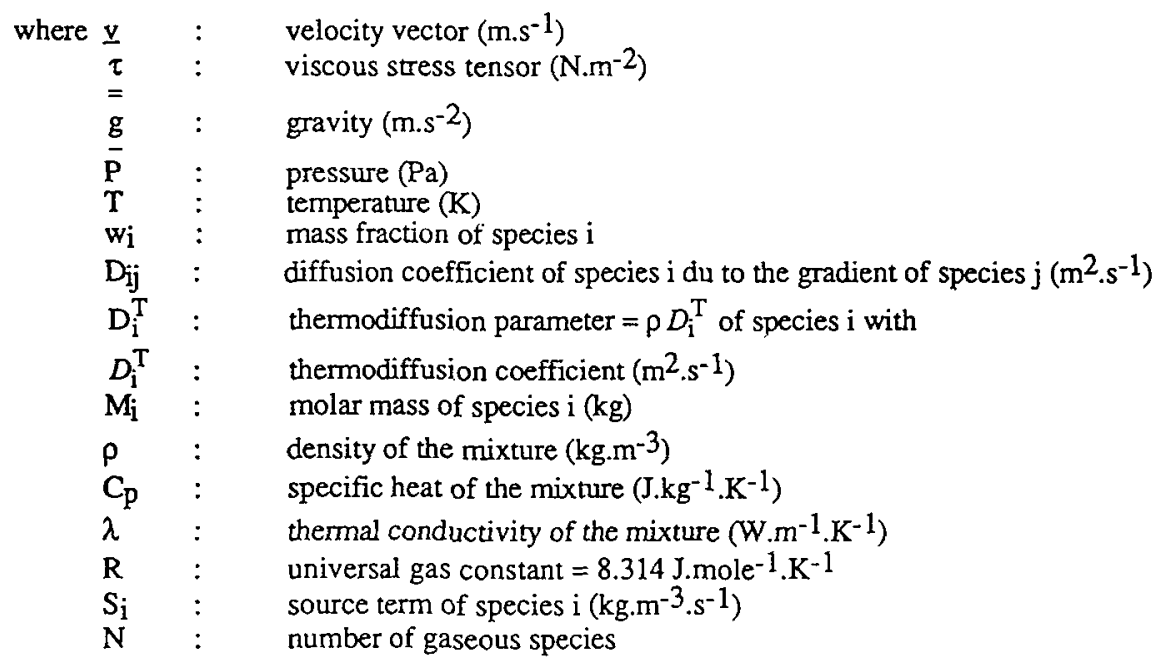


The boundary conditions for velocity and temperature are simple. At the inlet, the velocity of the mixture was specified in the axial direction as parabolic, and radial component of velocity was considered as zero. On solid surfaces, all velocities were assumed to be equal to zero. Temperature of $300 \mathrm{~K}$ and $1300 \mathrm{~K}$ were specified at the inlet, on the walls and on the substrate respectively. The mass fractions specified at the inlet come from a thermodynamic homogeneous equilibrium of the initial gas mixture $\left(\mathrm{Ar}(89 \%), \mathrm{H}_{2}(10 \%)\right.$, $\mathrm{SiH}_{4}(0.5 \%)$ and $\left.\mathrm{GeCl}_{4}(0.5 \%)\right)$. On cold walls, the mass fluxes were considered as zero. On the substrate, the mass fluxes, $R_{\mathrm{gi}}$ are linked with thermodynamic heterogeneous equilibrium. This last boundary condition lead to a complex situation. Contrarily to the model allowing the calculation of source terms by minimization and subsequent transformation, there is not conservation of the mass on the reactive substrate but $\mathrm{M}-1$ relations between gas and associated solid fluxes due to the conservation of the elements ( $M$ is the number of solids which could appear). The matrix $A$ is now defined by $E$ rows and $N+M$ columns. If $\mathrm{B}$ is the matrix defined by the conservation of the film composition, the boundary condition on the substrate is :

$$
\begin{aligned}
& \underline{\mathrm{n} .} \mathrm{J}_{\mathrm{i}}=\mathrm{Rg}_{\mathrm{i}} \quad \mathrm{i}=1 \ldots \mathrm{N}-1 \\
& \text { Minimization of } \mathrm{G}\left(\mathrm{P}, \mathrm{T}, \mathrm{w}_{1} \ldots \mathrm{w}_{\mathrm{N}-1}\right) \text { at each grid point } \\
& \underline{\mathrm{Rg} \in\langle\mathrm{A}\rangle^{\perp} \cap\langle\mathrm{B}\rangle}
\end{aligned}
$$

The $\underline{R} g$ vector at iteration $n+1$ is obtained by projection of the $\underline{R} g$ eq vector on the $\langle A\rangle^{\perp} \cap\langle B\rangle$ space. The $\mathrm{Rg}_{\text {eq }}$ vector is computed from a guessed equilibrium concentration field on the substrate at iteration $n$.

The equations (1)-(8) associated with boundary conditions and constraints described by equations (9)(12) are iteratively solved by finite element and minimization methods. Flux-Expert [21] and Melange [16] software packages were customized to solve the model.

\section{APPLICATION TO $\mathrm{Si}_{1-\mathrm{x}} \mathrm{Ge}_{\mathrm{x}}$ DEPOSITION}

The model predicts the flow and temperature fields of the mixture and the concentration fields of the gaseous species. The model also predicts the deposition rate and the stoichiometry of the deposited film. Figure 2(b) shows the predicted velocity and temperature fields inside the reactor when the substrate was set at $1300 \mathrm{~K}$, the inlet mixture was $\operatorname{Ar}(89 \%)-\mathrm{H}_{2}(10 \%)-\mathrm{SiH}_{4}(0.5 \%)-\mathrm{GeCl}_{4}(0.5 \%)$, e.g. $\mathrm{Y}_{\mathrm{Ge}}=0.5$, the total flow rate was $21 . \mathrm{mn}^{-1}$ and the pressure $315 \mathrm{~Pa}$. The predicted thermal profile (figure 2(c)) in the reactor shows that the temperature gradient is localized near the substrate due to convective effects. The most important gaseous species contributing to the film growth are $\mathrm{GeCl}, \mathrm{GeH}, \mathrm{Ge}(\mathrm{g}), \mathrm{Si}_{3}, \mathrm{Si}_{2}, \mathrm{Si}(\mathrm{g})$ and $\mathrm{SiH}$ when argon is the carrier gas (figure 3). These results revealed strong dependence of gas-phase equilibrium composition with the distance to the substrate. The film stoichiometry, $\mathrm{X}_{\mathrm{Ge}}$, is uniform and is about 0.18 along the substrate $\left(Y_{G e}=0.5\right)$. Simple previous equilibrium calculations predicted a minor depletion in germanium, $\mathrm{X}_{\mathrm{Ge}}=0.25$, for $\mathrm{Y}_{\mathrm{Ge}}=0.5$. These results evidences that the high thermodynamic stability of germanium chlorides, compared to silicon hydrides and chlorides, associated with mass transport phenomena deplete the film in germanium compared to the inlet germanium content.

Thermodiffusion plays an important role for the germanium containing species depletion of the gas phase near the substrate. Thermodiffusion causes heavier molecular weight species to be driven along a temperature gradient away from hot surfaces towards cold surfaces. The concentration of $\mathrm{GeCl}$, the most important gaseous species containing germanium, near the substrate is five times higher when thermodiffusion is neglected (figure 4). The thermal diffusion rates can be modified by changing the carrier gas. These results, assuming equilibrium conditions in a flowing system, should therefore be used for the identification of the reaction pathways and the influence of geometry, flow rate and temperature gradients but perhaps not for predicting the chemical composition of the film under actual operational conditions. 


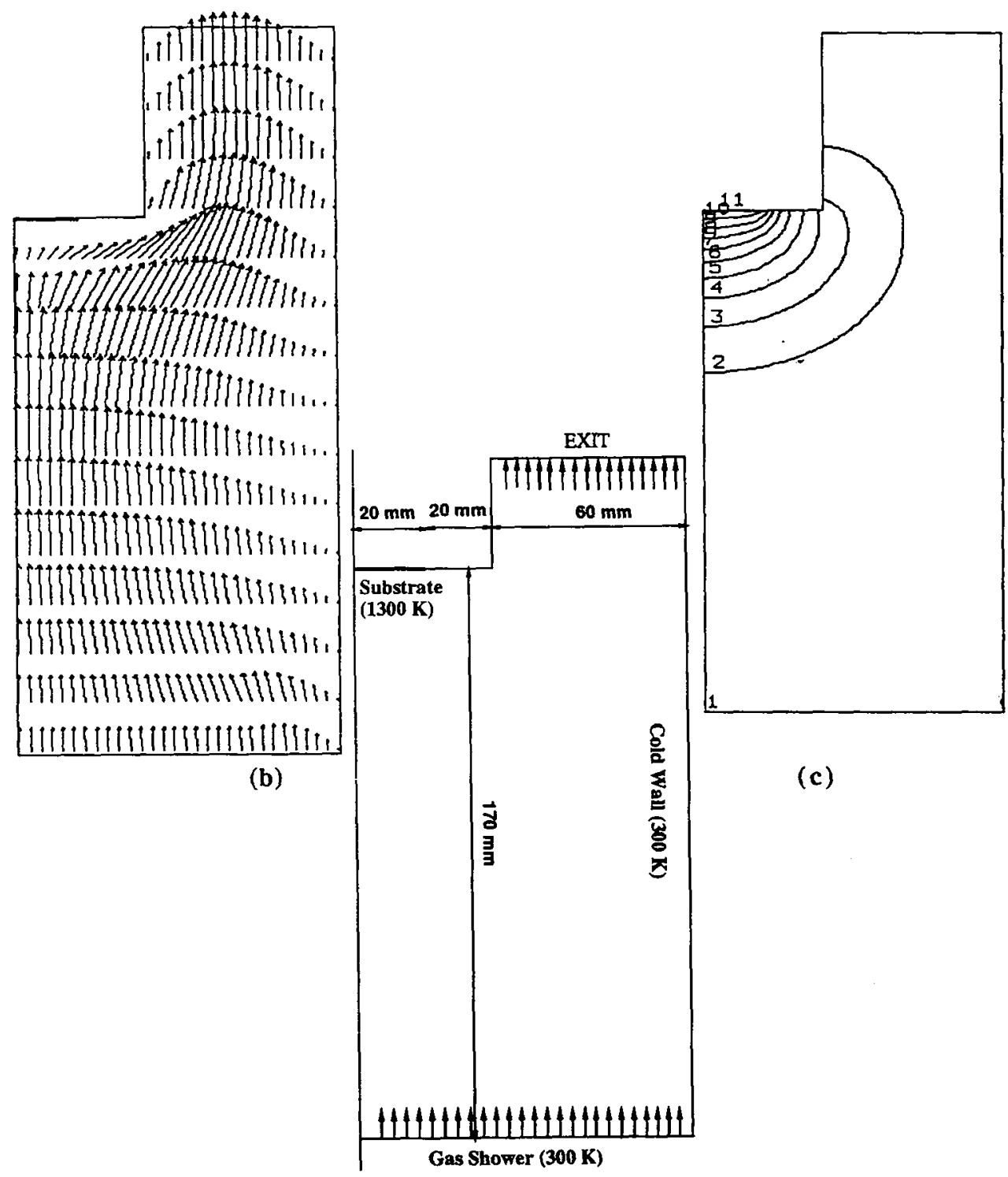

(a)

Figure 2 : (a) Schematic representation of the reactor, (b) velocity (b) and (c) temperature ( $1=300 \mathrm{~K} \ldots \ldots . . .11=1300 \mathrm{~K})$ fields : $\mathrm{T}_{\mathrm{S}}=1300 \mathrm{~K}$; inlet flow rate $: 2 \ell \cdot \mathrm{mn}^{-1} \mathrm{STP} ; \mathrm{P}=315 \mathrm{~Pa}$ 


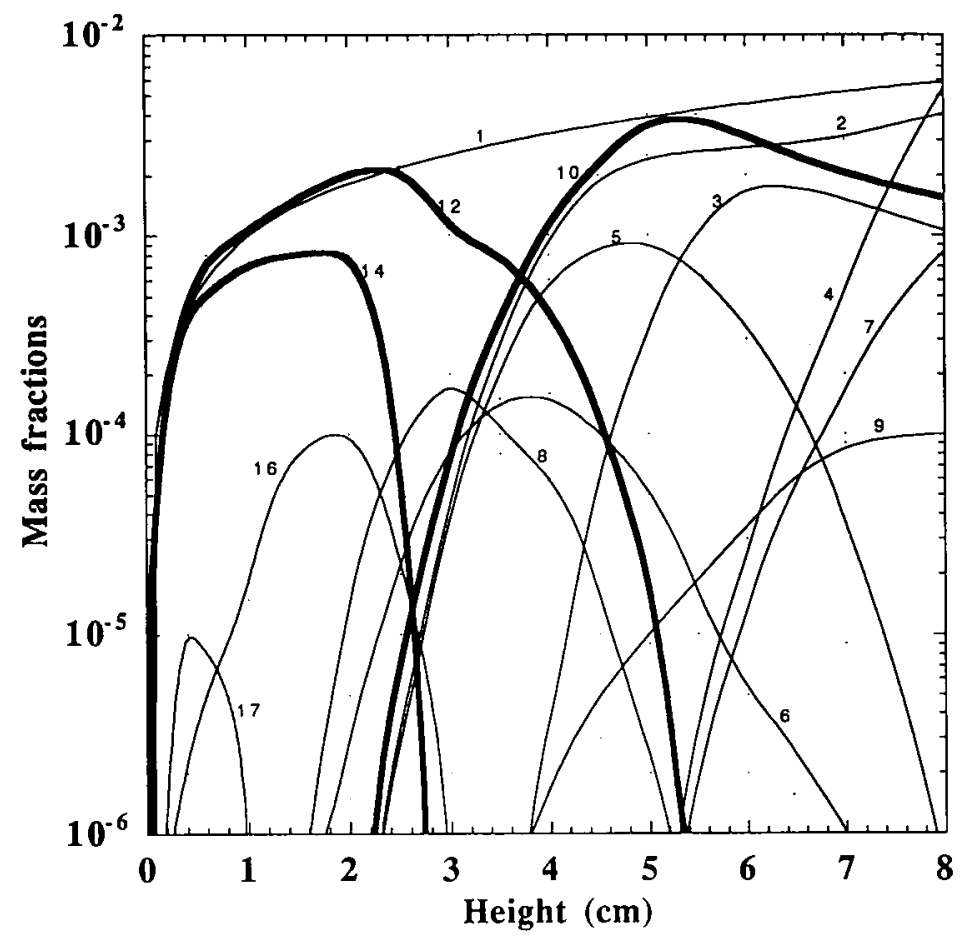

Figure 3 : Gaseous mass fractions along the centreline above the substrate (same experimental conditions as in figure 2). (1: $\mathrm{H}_{2} ; 2: \mathrm{GeH}_{4} ; 3: \mathrm{SiH}_{2} \mathrm{Cl}_{2} ; 4: \mathrm{SiHCl}_{3} ; 5: \mathrm{SiH}_{3} \mathrm{Cl} ; 6: \mathrm{SiH}_{4} ; 7: \mathrm{SiCl}_{4} ; 8: \mathrm{GeH}_{3} ; 9: \mathrm{GeH}_{3} \mathrm{Cl} ; 10: \mathrm{GeCl}_{3} ; 11:$ $\mathrm{Si}_{2} \mathrm{H}_{6} ; 12: \mathrm{GeCl} ; 13: \mathrm{SiCl}_{2} ; 14: \mathrm{Si}_{3} ; 15: \mathrm{HCl} ; 16: \mathrm{GeH} ; 17: \mathrm{Ge}(\mathrm{g}) ; 18: \mathrm{SiH} ; 19: \mathrm{SiCl}_{3} ; 20: \mathrm{SiH}_{4}$.

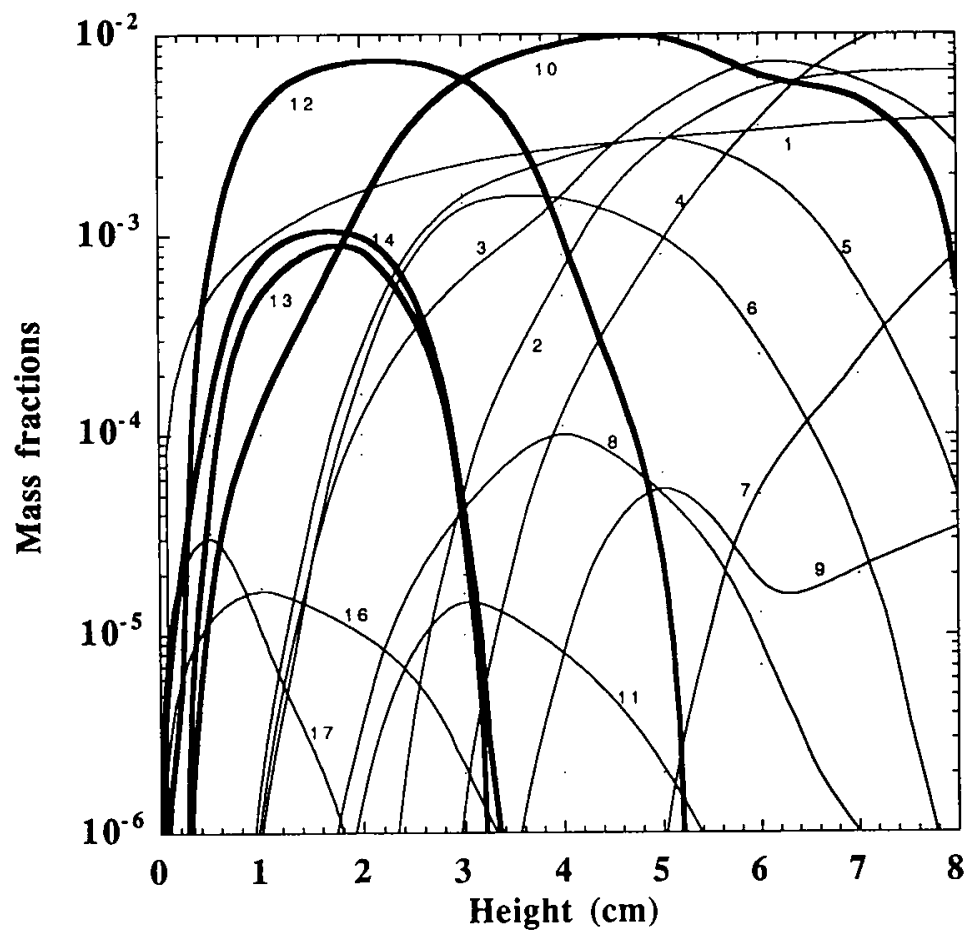

Figure 4 : Gaseous mass fractions along the centreline above the substrate (same experimental conditions as in figure 2 and 3): thermodiffusion was neglected 


\section{CONCLUSIONS}

A model linking near-local thermochemical equilibrium and mass transport was proposed and applied to $\mathrm{Si}_{1-\mathrm{x}} \mathrm{Ge}_{\mathrm{x}}$ deposition by germanium chloride, silane, hydrogen and argon mixture. It is built upon the physics of energy and mass movement and include a model for local equilibrium transformations within the system. It is a modelling route which offers insight into the physical and chemical causes and effects without writing out chemical pathways.

The modelling results indicate that the stoichiometry of the film is related to the thermodynamic stability of germanium chlorides and to their availability in the hot regions of the reactor. As a matter of fact, the fluxes of silicon containing species exceed that of germanium containing species $\left(\mathrm{X}_{\mathrm{Ge}}=0.18\right)$ when inlet ratio are $1: 1 \quad\left(\mathrm{Y}_{\mathrm{Ge}}=0.5\right)$ and when thermochemical equilibrium predicts $\mathrm{X}_{\mathrm{Ge}}=0.25$. For the used experimental conditions, it was found that the predicted results are in good agreement with the experimentally measured deposition rates. Then, the stoichiometry of the film could be predicted by such a model linking two different modelling approaches.

Assuming near-local thermochemical equilibrium within the flowing system could provide useful information for the identification of phenomena which control the film growth. This modelling route could also provide an assessment of the experimental method and a framework into which a kinetic-mass transport model could fit.

\section{References}

[1] Jensen K.F., in Microelectronics Processing : Chemical Engineering Aspects, D.W. Hess and K.F Jensen Eds., Advances in Chemistry Series 221 (American Chemical Society, Washington DC, 1989) pp. 199-263.

[2] Kleijn C.R., Werner C., Modeling of Chemical Vapor Deposition of Tungsten Films (Birkhaüser, Verlag, 1993).

[3] Pons M., Bernard C., Madar R., Surf. Coat. Technol., 61 (1993) 274-281.

[4] D. E. Rosner, J. Collins, in Chemical Vapor Deposition of Refractory Metals and Ceramics, edited by T.M. Besmann and B.M. Gallois Eds. (Materials Research Society Symp. 168, Pittsburgh, PA, 1990) pp 43-48.

[5] Gokoglu S.A., J. Electrochem. Soc., 135 (1988) 1562-1570.

[6] D. Zhu D., Y. Sahai Y., Metall. Trans., 322 (1991) 309-321.

[7] Pons M., J.N. Barbier, C. Bernard, R. Madar, Appl. Surf. Sci., 73 (1993) 71-81.

[8] Spear K.E., Dirkx R.R., High. Temp. Sci., 27 (1990) 107-129.

[9] Coltrin M.E., Kee R.J., Miller J.A., J. Electrochem. Soc., 133 (1986) 1206-1214.

[10] Couderc J.P., Duverneuil P., J. Electrochem. Soc., 139 (1992) 296-304.

[11] Allendorf M.D., Kee R.J., J. Electrochem. Soc., 138 (3) (1991) 841-852.

[12] Wang Y.B., Teyssandier F., Simon J., Feurer R., J. Electrochem. Soc., 141 (3) (1994) 824-842.

[13] Mountziaris T.J., Jensen K.F., J. Crystal Growth, 138 (1991) 2426-2439.

[14] Frenklach M., Wang H., Phys. Rev., B43 (1991) 1520-1545.

[15] E. Blanquet E., Gokoglu S.A., in CVD-XII International Symposium on Chemical Vapor Deposition, K.F. Jensen and G.W. Cullen Eds., Proceeding Volume 93-2 (The Electrochemical Society, Pennington, NJ, 1993) pp 103-109.

[16] Barbier J.N., Bernard C., Proceedings of the $15^{\text {th }}$ Calphad Meeting, B.L. Kaufman Eds., Calphad (1986) 206-210.

[17] SGTE databank, Scientific Group Thermodata Europe, BP 66, 38402 Saint-Martin d'Hères, France.

[18] Ho P., Coltrin M.E., Binkley J.S., Melius C.F., J. Phys. Chem., 89 (1985) 4647-4654.

[19] H. Rouch, PhD Thesis, Institut National Polytechnique de Grenoble, 1994.

[20] Bergman C., Chastel R., Castanet R., J. Phase Equi., 13, (1992) 113-118.

[21] Flux Expert, DT2I, Chemin des Prèles, 38240 Meylan, France, 1994. 